\title{
Prevalence and Correlates of Violence against Women in Nepal: Findings from Nepal Demographic Health Survey, 2011
}

\author{
Absar Ahmad, Abdul Jaleel \\ International Institute for Population Sciences (IIPS), Mumbai, India \\ Email: crabsar@gmail.com, cpjaleel@gmail.com \\ Received 8 February 2015; accepted 28 March 2015; published 31 March 2015 \\ Copyright $(\subset 2015$ by authors and Scientific Research Publishing Inc. \\ This work is licensed under the Creative Commons Attribution International License (CC BY). \\ http://creativecommons.org/licenses/by/4.0/ \\ (c) (i) Open Access
}

\begin{abstract}
Using data from a nationally representative sample of 3224 ever-married women interviewed as part of Nepal Demographic Health Survey-2011, this paper examined the prevalence and correlates of violence against women in Nepal. Results showed that one out of every two ever-married women aged 15 - 49 of the country experienced violence of any kind in their life. Odds of experiencing violence are higher among women of rural areas, women having low economic and educational status, and separated/divorced women. Having more children and alcohol consuming husbands also increase women's chance of being victimised of violence in Nepal.
\end{abstract}

\section{Keywords}

Violence against Women, Nepal Demographic Health Survey (NDHS), Ever-Married Women, Nepal

\section{Introduction}

The term violence against women, domestic violence, domestic abuse, intimate partner violence and spousal violence is often used interchangeably (see Fischbach \& Herbert, 1997; Hindin, Kishor, \& Ansara, 2008). The United Nations Declaration on the Elimination of Violence Against Women (1993) provided a consensus definition of violence against women as "any act of gender-based violence that results in, or is likely to result in, physical, sexual, or psychological harm or suffering to women, including threats of such acts, coercion or arbitrary deprivation of liberty, whether occurring in public or private life” (p. 2). Violence against women takes a variety of forms physical, psychological, or economic; it includes acts of violence or the threat of such acts.

Violence against women is one of the most pervasive of human rights violations, denying women and girl's equality, security, dignity, self-worth, and their right to enjoy fundamental freedoms. Global agencies have 
raised their concern over increasing violence against women and called for stern government actions. According to the United Nations Children's Fund (UNICEF, 2000), violence against women and girls continues to be a global epidemic that kills, tortures and maims physically, psychologically, sexually and economically. The Council of Europe (2006) reported that domestic violence is the major cause of death and disability for women between the ages of 16 and 44. World Health Organization (WHO, 2002) also found that as many as 70 percent of all "femicides" are committed by the victims' male partners, and approximately a third of all girls are forced or coerced into their first sexual experience. By taking all these into account, through Millennium Development Goals, the United Nations (2000) has responded against this issue by calling its 191 member states for sustainable human development by recognising equal rights and opportunities for women and men.

Violence against women takes place in all societies regardless of races, social and economic backgrounds, cultures and religions. Although it affects all countries, its prevalence varies substantially (see Bott, Morrison, \& Ellsberg, 2005; Moreno, Jansen, Ellsberg, Heise, \& Watts, 2005; Hindin et al., 2008). One out of every three women in the world has been beaten, coerced into sex, or otherwise abused in her lifetime and the abuser is usually a family member or someone otherwise known to her (Heise, Ellsberg, \& Gottemoeller, 1999). Tjaden and Thoennes (2000) found that approximately 25 percent of women in the United States experience intimate partner violence in their lifetime. A multi-country study conducted by World Health Organization (2006) on women’s health and domestic violence found that life time prevalence of physical and sexual violence by an intimate partner varies between 15 percent (Japan) and 71 percent (Ethiopia) and prevalence of such violence within the past year varies between four percent (Japan) and 53 percent (Ethiopia).

Violence and discrimination against women is pervasive in all countries of the south Asia. The gender-related development index (GDI) is lower than the human development index (HDI) in every south Asian countries. Survey based studies have found higher prevalence of domestic violence in all the countries. From 35 to 75 percentages of women in India face verbal, physical, or sexual violence from their partners or other men known to them (see Jejeebhoy, 1998; Mahajan, 1990; Karlekar, 1998; Visaria, 2000). According to National Family Health Survey (NFHS-3) by International Institute for Population Sciences (2007), one-third of women aged 15 - 49 have experienced physical violence in India and about one in 10 have experienced sexual violence. Overall, 35 percent have experienced physical or sexual violence. The "Violence against Women Survey-2011" conducted by the Bangladesh Bureau of Statistics in collaboration with the United Nations Population Fund found that about 87 percent of Bangladeshi married women are abused by their husband. A study conducted in urban Pakistan by Ali et al. (2011) also reports that prevalence of violence against women is 56 percent for the past year and 58 percent for lifetime. The corresponding figures for sexual violence are 53 and 55 percent respectively, and for psychological abuse are 82 and 84 percent respectively.

In Nepal, many studies on violence against women have already been carried. But, the estimates produced on violence against women by each study are different from the other (see Adhikari et al., 2010; Puri et al., 2012; Axinn et al., 2013). Adhikari et al. (2010) found that prevalence of sexual violence experienced by ever-married women from their husbands is 58 percent. At the same time, a cross-sectional study conducted by Puri et al. (2012) among 1296 young married women aged 15 - 24 years provide an estimate of life time experience of sexual violence as 52 percent and experience of some form of violence in the past 12 months as 36 percent. Study by Axinn et al. (2013) brought an estimation that 35 percent of women in Nepal experience gender-based violence at home. There have been attempts to understand the causes of violence against women in Nepal. A study conducted by Sharma (2007) on the cause of domestic violence in Nepalese society found alcoholism as a major factor. As per his estimate, 42 percent of the women are victimis of domestic violence due to alcoholism of their husband. The findings of Adhikari et al. (2010) were also consistent where he found that literacy status of women and alcohol consumption by the husband are the major risk factors of violence. Lamichhane et al. (2011) found that no or little inter-spousal communication and low autonomy of women significantly increase the odds of experiencing violence in Nepal.

Although, violence against women is rampant in the country, it is hidden inside the four walls of the home. Most of the violence go unreported and unrecorded in informal or formal institutions. Explaining this, Joshi and Kharel (2008) opined that in Nepal, violence against women is virtually invisible due to the shame of women to discuss it in public or because they consider this as part of the culture. The culture of silence along with the close legal relationship with the abuser (usually the abuser is a family member or someone otherwise known to her) and the victim blaming attitudes stop women from reporting their experience of violence. Women often keep silence of such acts to maintain family prestige and privacy, love and affection with husband and family 
members, fear of husband and mother-in-law, fear of breaking family relation. Fear of social, traditional and cultural values, fear of further beating, physical assault, marginalization, uncertainty of justice, lack of faith in justice, etc. are the other reasons that stop women from reporting their plights. Men use threats of abandonment, seeking sexual gratification elsewhere, remarriage and quarrel to force sex upon wives early in the marriage. Responding to the issue, Parliament of Nepal passed the Domestic Violence (Crime and Punishment) Act in the year 2009. This Act includes physical and psychological violence within the definition of domestic violence. The Act also states that the reporting of a crime can be made both verbal or in written forms, and a third party can also file a report on behalf of the victim.

Despite the importance of the problem, the number of studies with nationally representative samples in Nepal is limited. Most of the earlier studies were conducted with small samples and the findings could not be generalized for the country and thus there is a need to understand the magnitude and nature of the different forms of violence against women in Nepal. Information on violence against women was collected for the first time through the fourth Nepal Demographic Health Survey (NDHS) conducted in the year 2011. This survey addressed less severe, severe and sexual violence against 15 - 49 aged women. The present paper examined the prevalence and associated factors of violence against ever-married women in Nepal. The purpose of this paper is to understand the magnitude of violence against women in Nepal, to identify the major perpetrators and factors leading to violence against women.

\section{Materials and Methods}

Data from Nepal Demographic Health Survey, 2011 is used for this analysis. This survey is the fourth in the series and it is nationally representative conducted as part of the worldwide Demographic and Health Surveys (DHS) project. New-ERA implemented the survey under the aegis of the Population Division, Ministry of Health and Population. Technical support for this survey was provided by ICF International and financial support from the United States Agency for International Development (USAID).

\subsection{Participants}

This survey collected demographic and health information from a nationally representative sample of 10,826 households, which yielded completed interviews with 12,674 women aged 15 - 49 years in all selected households. A total 4121 men age 15 - 49 were interviewed in every second household. The domestic violence module was implemented only in the sub-sample of households selected for the men's survey. Further, in keeping with ethical requirements only one woman per household was selected for the module. Information on domestic violence was obtained from ever-married women on violence committed by their current and former spouses and others, and information was collected from never-married women on violence by anyone, including boyfriends. A total of 4210 women being eligible for the survey, of whom 4197 were successfully interviewed. Out of 4197, ever-married women were 3224. Specially constructed weights were used to adjust for the selection of only one woman per household and to ensure that the domestic violence subsample is nationally representative.

\subsection{Selection of Samples}

Nepal is administratively divided into 75 districts, which are further divided into smaller administrative units known as Village Development Committees (VDCs) and Municipalities. The VDCs and municipalities are further divided into wards. The larger wards in the urban areas are further divided into sub-wards. An enumeration area (EA) is defined as a ward in the rural areas and a sub-ward in the urban areas. Each EA is totally classified as urban or rural. The country is broadly divided into three horizontal ecological belts, namely, Mountain, Hill, and Terai. Vertically the country is divided into five development regions. The cross section of these will provide 13 eco-development regions, which are referred to as sub-regions or domains for the 2011 NDHS. Stratification is achieved by separating each of the 13 domains into urban and rural areas.

Samples were selected independently in every stratum, through a two-stage selection process. In the first stage, EAs were selected using a probability proportional-to-size. A complete household listing and mapping was carried out in all selected clusters. In the second stage, 35 households in each urban EA and 40 households in each rural EA were randomly selected. Due to the non-proportional allocation of the sample to the different domains and to over sampling of urban areas in each domain, sampling weights are required for any analysis using 2011 
NDHS data to ensure the actual representativeness of the sample at the national level as well as domain levels. Since the 2011 NDHS sample is a two-stage stratified cluster sample, sampling weights were calculated based on sampling probabilities separately for each sampling stage taking into account the non-proportionality in the allocation process for domains and urban-rural strata.

\subsection{Questionnaire}

For data collection, three questionnaires were administered in the 2011 NDHS: the Household Questionnaire, the Woman's Questionnaire, and the Man's Questionnaire. The Woman's Questionnaire was used to collect information from women age 15 - 49. Written consent was taken from each respondent before interview. Ethical approval was obtained from the Nepal Health Research Council, Nepal and IFC Macro Institutional Review Board in Calverton, MD, USA.

\subsection{Questions about Violence against Women}

Information was obtained from ever-married women on violence committed by their current and former spouses and by others, and information was collected from never-married women on violence by anyone, including boyfriends. Since international research shows that intimate partner violence is one of the most common forms of violence against women, information on spousal violence was measured in more detail than violence by other perpetrators. This was done by using a shortened and modified version of the Conflict Tactics Scale (Strauss, 1990). Specifically, spousal violence by the most current husband/partner for currently married women and the most recent husband/partner for formerly married women was measured by asking all ever-married women the following set of questions. (Does/did) your (last) (husband/partner) ever:

(a) Push you, shake you, or throw something at you?

(b) Slap you?

(c) Twist your arm or pull your hair?

(d) Punch you with his fist or with something that could hurt you?

(e) Kick you, drag you, or beat you up?

(f) Try to choke you or burn you on purpose?

(g) Threaten or attack you with a knife, gun, or any other weapon?

(h) Physically force you to have sexual intercourse with him even when you did not want to?

(i) Force you to perform any sexual acts you did not want to?

For every question that a woman answered "yes", she was asked about the frequency of the act in the 12 months preceding the survey. A "yes" answer to one or more of items (a) to (g) above constitutes evidence of physical violence, and a "yes" answer to item (h) or (i) constitutes evidence of sexual violence. Similarly, emotional violence among ever-married women was measured by the following questions. (Does/did) your (last) (husband/partner) ever: (a) Say or do something to humiliate you in front of others? (b) Threaten to hurt or harm you or someone close to you? (c) Insult you or make you feel bad about yourself?

This approach of asking about specific acts to measure different forms of violence has the advantage of not being affected by different understandings of what constitutes a summary term such as "violence”. By including a wide range of acts, this approach has the additional advantage of giving the respondent multiple opportunities to disclose any experience of violence. In addition to these questions that were asked only of ever-married women, all women were asked about physical violence from persons other than the current or most recent spouse/partner. Respondents who answered "yes” to this question were asked who committed violence against them and the frequency of such violence during the 12 months preceding the survey. Women who reported experiencing different forms of violence were asked for the perpetrators of the violence. Although this approach to questioning is generally considered to be optimal, the possibility of underreporting of violence, particularly sexual violence, cannot be entirely ruled out in any survey, and this survey is exception.

\subsection{Analysis}

Statistical analysis is carried out in SPSS 20.0 and Microsoft excel. Binary logistic regression analysis is used to see the relationship of household and individual characteristic (independent variables) on less severe violence, severe violence and sexual violence (dependent variables). Women's age, educational, working and marital 
statuses, number of living children, place of residence, region, religion and wealth index are used as individual and household characteristics. The p-value of 0.05 is considered significant.

The acts included in each type of domestic violence are as follows:

\begin{tabular}{cl}
\hline Types of domestic violence & \multicolumn{1}{c}{ Acts included } \\
\hline Less severe violence & $\begin{array}{l}\text { Experiences of women such as ever pushed, shook, thrown, slapped, punched, } \\
\text { arm twisted and hair pulled to women. }\end{array}$ \\
Severe violence & Experiences such as kicked, dragged, and threatened with knife/gun or other weapon to women. \\
Sexual violence & Forced for unwanted sex or other unwanted sexual act. \\
\hline
\end{tabular}

\section{Results}

Table 1 presents the percentage of ever-married women who have experienced different types of domestic violence (less severe, severe and sexual), differentiated by their social, economic and demographic characteristics. As shown in Table 1, near half (47\%) of the ever-married women aged 15 - 49 have experienced some violence (less severe $23 \%$, severe $10 \%$ and sexual $14 \%$ ) in their lifetime. In other words, lifetime prevalence of violence against women is 47 percent in Nepal. This indicates that the domestic violence is common (one out of every two ever-married women aged 15 - 49 are victims of domestic violence) in the country. Prevalence of violence segregated by women's age shows high prevalence of violence for aged (40 - 49) women with respect to young (15 - 19) women. The prevalence of "less severe violence" is 16 percent for ever-married women of age 15 - 19 while this is 26 percent for ever-married women of age 40 - 49. Likewise, the prevalence of "severe violence" and "sexual violence" is six and 12 percent respectively for ever-married women of age 15 - 19 and 15 percent respectively for ever-married women of age 40 - 49. This higher prevalence for aged women may be due to the cumulative effect of violence experienced by woman throughout her lifetime. Category wise, prevalence of violence is 70 percent for employed women and 67 percent for divorced, separated or widowed women. Those women having more number of living children experienced more violence in Nepal. Prevalence of less severe violence is 15 percent for women with no children, and this is 34 percent for women with five or more children. Similarly, the prevalence of severe violence is only seven percent for women with no children and 19 percent for women with five or more children. As far as prevalence of sexual violence is concerned, this is 12 percent for women with no children and 23 percent for women with five or more children. This indicates that all the three types of violence is higher for women having more children (five or more). The prevalence of all the three types of violence is high for women of the Terai region (51\%) than women of other regions, viz. hill and mountain. Prevalence of violence is high among uneducated women compared to educated women. Thus, it can be said that the education of women will reduce the occurrence of violence. Prevalence of less severe violence is high among women from medium wealth quintile (30 percent) and less among women from richest wealth quintile (12 percent). Prevalence of severe violence is more among women from poor wealth quintile (13 percent) and less among women from richest wealth quintile (4 percent). Likewise, prevalence of sexual violence is also high among women from poor wealth quintile (17 percent) and less among women from rich wealth quintile (10 percent).

Table 1 also shows the results of chi-square test for independence to determine whether ever-married women's: age, working status, marital status, number of living children, region, educational status, religion and wealth quintile are related to less severe, severe and sexual violence. It is used to determine whether there is a significant association between all these variable with three types of violence. The result shows age of evermarried women are significantly associated with less severe and severer violence. Working status of women is significantly associated with severe violence, and marital status and region are significantly associated with severe and sexual violence. Variables such as number of living children a woman have, educational status, religion and wealth quintiles are significantly associated with all three types of violence. In short, the overall prevalence of violence against ever-married women is 47 percent in Nepal and 51 percent for Terai region. In Nepal, out of every 100 ever-married women, 47 have experienced any type of violence in their lifetime in which 24 have been victims of severe violence or sexual violence. Findings suggest that employed women are more likely to be the victims of violence in Nepal. This may be indicative of the fact that women are forced to take up employment, or the employment status of women in Nepal may be distress driven in nature. Since it is the poor women (less 
Table 1. Percentage of ever-married women aged 15 - 49 who experienced violence by background characteristics in Nepal, 2011.

\begin{tabular}{|c|c|c|c|}
\hline \multirow{2}{*}{ Background characteristics } & \multicolumn{3}{|c|}{ Type of violence } \\
\hline & Les severe & Severe & Sexual \\
\hline \multicolumn{4}{|l|}{ Age } \\
\hline $15-19$ & $16.1^{*}$ & $5.7^{* *}$ & 11.9 \\
\hline $20-24$ & $19.7^{*}$ & $9.2^{* *}$ & 12.6 \\
\hline $25-29$ & $22.4^{*}$ & $9.3^{* *}$ & 13.6 \\
\hline $30-34$ & $23.9^{*}$ & $9.7^{* *}$ & 16.1 \\
\hline $35-39$ & $24.7^{*}$ & $11.2^{* *}$ & 14.6 \\
\hline $40-44$ & $26.6^{*}$ & $11.9^{* *}$ & 15.9 \\
\hline $45-49$ & $25.9^{*}$ & $15.3^{* *}$ & 14.8 \\
\hline \multicolumn{4}{|l|}{ Working status } \\
\hline No & 21.9 & $7.7^{* *}$ & 12.9 \\
\hline Yes & 23.3 & $11.6^{* *}$ & 14.9 \\
\hline \multicolumn{4}{|l|}{ Marital status } \\
\hline Married & 22.7 & $9.8^{* *}$ & $14.0^{*}$ \\
\hline Divorce/separated/widow & 26.4 & $20.7^{* *}$ & $20.0^{*}$ \\
\hline \multicolumn{4}{|l|}{ No of living children } \\
\hline 0 & $14.6^{* *}$ & $6.8^{* *}$ & $11.9^{* *}$ \\
\hline $1-2$ & $19.8^{* *}$ & $7.8^{* *}$ & $12.2^{* *}$ \\
\hline $3-4$ & $26.5^{* *}$ & $12.0^{* *}$ & $15.4^{* *}$ \\
\hline $5+$ & $33.8^{* *}$ & $19.2^{* *}$ & $22.5^{* *}$ \\
\hline \multicolumn{4}{|l|}{ Residence } \\
\hline Urban & 20.7 & $8.3^{*}$ & $12.5^{*}$ \\
\hline Rural & 23.5 & $10.9^{*}$ & $14.9^{*}$ \\
\hline \multicolumn{4}{|l|}{ Region } \\
\hline Mountain & $17.6^{* *}$ & $9.0^{* *}$ & $14.0^{* *}$ \\
\hline Hill & $17.4^{* *}$ & $8.5^{* *}$ & $11.0^{* *}$ \\
\hline Terai & $30.1^{* *}$ & $12.6^{* *}$ & $18.0^{* *}$ \\
\hline \multicolumn{4}{|l|}{ Level of education } \\
\hline No education & $30.3^{* *}$ & $13.4^{* *}$ & $17.2^{* *}$ \\
\hline Primary & $19.4^{* *}$ & $8.5^{* *}$ & $12.1^{* *}$ \\
\hline Secondary & $15.4^{* *}$ & $7.5^{* *}$ & $11.1^{* *}$ \\
\hline Higher & $7.1^{* *}$ & $3.3^{* *}$ & $10.9^{* *}$ \\
\hline \multicolumn{4}{|l|}{ Religion } \\
\hline Hindu & $22.0^{* *}$ & $9.8^{* *}$ & $14.1^{* *}$ \\
\hline Buddhist & $16.6^{* *}$ & $8.3^{* *}$ & $10.4^{* *}$ \\
\hline Muslim & $55.2^{* *}$ & $23.2^{* *}$ & $25.0^{* *}$ \\
\hline Other & $32.6^{* * *}$ & $17.9^{* *}$ & $18.9^{* *}$ \\
\hline \multicolumn{4}{|l|}{ Wealth Index } \\
\hline Poorest & $23.4^{* *}$ & $11.0^{* *}$ & $14.4^{* *}$ \\
\hline Poorer & $26.7^{* *}$ & $13.4^{* *}$ & $17.2^{* *}$ \\
\hline Middle & $30.1^{* *}$ & $12.0^{* * *}$ & $16.2^{* *}$ \\
\hline Richer & $23.6^{* *}$ & $11.5^{* *}$ & $14.2^{* *}$ \\
\hline Richest & $12.0^{* * *}$ & $4.3^{* *}$ & $10.3^{* *}$ \\
\hline Total & 22.8 & 10.3 & 14.3 \\
\hline
\end{tabular}

Note: *Significantat $5 \%$ level of significance; ${ }^{* *}$ Significant at $1 \%$ level of significance. 
educated, having more number of children and from the lowest wealth quintiles) who experience more violence in Nepal, the potential conclusion can be drawn is that social and economic status of women have a significant role in the occurrence of violence.

Table 2 presents the perpetrators of violence against women differentiated by type of violence. The most commonly reported perpetrator of all the three types of violence is the current husband (14, 30 and 22 percentages respectively for less severe, severe and sexual violence). This indicates the occurrence of a high level of spousal violence in Nepal and the finding is consistent with the assumption that women are more likely to be abused by an intimate partner than by any other person. Although, most of the violence is intimate partner violence in Nepal, mothers and fathers are also involved in committing violence against their daughters. "Other in laws" and "other relatives" also perpetuate violence against women. Perpetrators of violence against women in Nepal follow the order: own family members (husband, father, mother and brother/sister), in-laws (fatherin-law, mother-in-law and other in-laws), other relatives and former husband and "others" (teacher, employer and others). Thus, the presupposition we hold with respect to violence against women that it is the intimate partner who often commit violence against women is true in the case of Nepal also.

Table 3 presents the result of the binary logistic regression model. This model is used to estimate the likelihood of an ever-married woman of being victimized of violence (less severe, severe and sexual) in Nepal. The model is used here to address the question "how the likelihoods of being victimized of violence vary by social, economic and demographic attributes of ever-married women in Nepal?” This is assessed by using logistic regression models separately for experience of less severe, severe and sexual violence. The dependent (outcome) variables used in the model are "less severe violence", "severe violence" and "sexual violence" and the independent (predictor) variables are "working status", "marital status”, "number of living children”, "region” and "religion”. Results show that divorced/separated/widowed women, ever-married women from Terai region and Muslims community, women with five or more living children and woman with an alcoholic husband are more likely to be the victims of violence in Nepal. Odds for experiencing severe violence are four times higher for Muslim women with respect to Hindu women, three times higher for women whose husbands are alcoholic with respect to a woman having a non-alcoholic husband and twice higher each for women who are divorced/separated/ widowed with respect to currently married women and women with five or more living children with respect to women having no child. However, odds for experiencing sexual violence are concerned, it is two times higher

Table 2. Percentage of ever - married women aged 15 - 49 who experienced violence differentiated by perpetuators in Nepal, 2011.

\begin{tabular}{|c|c|c|c|}
\hline \multirow{2}{*}{ Person involved } & \multicolumn{3}{|c|}{ Type of violence } \\
\hline & Les severe & Severe & Sexual \\
\hline Husband & 13.74 & 30.42 & 21.91 \\
\hline Mother & 6.39 & 14.16 & 10.20 \\
\hline Father & 6.53 & 14.46 & 10.41 \\
\hline Sister/brother & 5.71 & 12.65 & 9.11 \\
\hline Other relatives & 4.22 & 9.34 & 6.72 \\
\hline Former partner & 1.77 & 3.92 & 2.82 \\
\hline Mother in law & 2.99 & 6.63 & 4.77 \\
\hline Father in law & 3.27 & 7.23 & 5.21 \\
\hline Other in law & 5.17 & 11.45 & 8.24 \\
\hline Teacher & 0.82 & 1.81 & 1.30 \\
\hline Employer & 0.54 & 1.20 & 0.87 \\
\hline Others & 1.36 & 3.01 & 2.17 \\
\hline Total & 735 & 332 & 461 \\
\hline
\end{tabular}


Table 3. Binary logistic regression analysis of reason for less severe, severe and sexual violences in Nepal, 2011.

\begin{tabular}{|c|c|c|c|}
\hline \multirow{2}{*}{ Background characteristics } & \multicolumn{3}{|c|}{ Type of violence } \\
\hline & Les severe Exp. (B) & Severe Exp. (B) & Sexual Exp. (B) \\
\hline \multicolumn{4}{|l|}{ Working status } \\
\hline \multicolumn{4}{|l|}{ No } \\
\hline Yes & 1.134 & $1.519^{* *}$ & 1.257 \\
\hline \multicolumn{4}{|l|}{ Marital status } \\
\hline \multicolumn{4}{|l|}{ Married } \\
\hline Divorce/separated/widow & 0.972 & $2.107^{* *}$ & $1.617^{*}$ \\
\hline \multicolumn{4}{|l|}{ No of living children } \\
\hline \multicolumn{4}{|l|}{0} \\
\hline $1-2$ & 1.232 & 1.025 & 0.961 \\
\hline $3-4$ & 1.274 & 1.313 & 1.157 \\
\hline $5+$ & $1.674^{*}$ & $2.043^{*}$ & $1.946^{*}$ \\
\hline \multicolumn{4}{|l|}{ Regions } \\
\hline \multicolumn{4}{|l|}{ Mountain } \\
\hline Hill & 0.993 & 0.992 & 0.762 \\
\hline Terai & $2.356^{* *}$ & $1.834^{* * *}$ & $1.531^{*}$ \\
\hline \multicolumn{4}{|l|}{ Religion } \\
\hline \multicolumn{4}{|l|}{ Hindu } \\
\hline Buddhist & $0.67^{*}$ & 0.735 & 0.684 \\
\hline Muslim & $4.503^{* *}$ & $4.145^{* *}$ & $1.989^{*}$ \\
\hline Other & $1.921^{* *}$ & $2.234^{* *}$ & 1.407 \\
\hline Husband consumes alcohol & $2.728^{* *}$ & $2.926^{* *}$ & $2.207^{* *}$ \\
\hline
\end{tabular}

Note: ${ }^{*}$ Significant at $5 \%$ level of significance; ${ }^{* *}$ Significant at $1 \%$ level of significance; Controlled for age, residence, education level, wealth index.

for women with alcoholic husbands, two times higher for Muslim women and women with five or more living children, 1.6 times higher for divorced/separated/widowed and one and half times higher for women from Terai region. Furthermore, it is found that experience of all the three types of violence is significantly associated with women whose husbands consume alcohol. This indicates that the alcohol consumption of husband increases a woman's probability of being victimised of violence in Nepal.

\section{Discussion and Conclusion}

This paper examined the prevalence of less severe, severe and sexual violence against ever-married women in Nepal by using a nationally representative sample of 3224 ever-married women. We found that the prevalence of less severe, severe and sexual violence are markedly high (47\% of ever-married women aged 15 - 49) in Nepal. Our result regarding the estimate of the prevalence of violence against women is low (less severe violence $23 \%$, severe violence $10 \%$ and sexual violence $14 \%$ ) as compared to some of the earlier studies. For instance, as per the estimation by Tamang (2009), prevalence of domestic violence was 52 percent and sexual violence was 46 percent. Puri et al. (2012) given an estimate for prevalence of sexual violence at some point in their life and prevalence of sexual violence in the past 12 months as 46 and 31 percent respectively. However, our study confirms some of the findings of previous studies particularly regarding the risk factors of sexual violence. Many 
studies have found that women's low educational attainment and household's low social and economic status are the significant predictors of sexual violence in Nepal. As per our analysis, less educated women and women from economically poor households are more likely to be the victims of all the three types of violence. Further, odds of experiencing violence increase when women have five or more children and have an alcoholic husband. In Nepal, the main perpetrator of violence is the current husbands. Own father and mother, other in-laws and other relatives are also commit violence against women. This shows that not only husbands and in-laws is involved in committing violence against women, but almost equally by very close family members such as father and mother.

This paper has brought out the magnitude, nature and causes of violence against women in Nepal, the prevalence of less severe, severe and sexual violence along with risk factors for being the victim of violence by ever-married women. It is important to understand the context in which violence against women takes place so that the state and society can ensure that women's human rights are not been violated. It is found in this analysis that the prevalence of violence is high for women of economically poor households and women with less education. This suggests that social and economic development can be a good leveler to reduce the occurrence of violence against women in Nepal. Therefore, government and other stakeholders need to be focused on education of girls and improving women's financial capability to make them empowered. The higher prevalence of violence among Muslim women and women from Terai region propose the need of better inclusion by ensuring better delivery of services towards underserved population. Along with these, the intervention of the state is crucial to stop this injustice by strengthening the domestic violence act in the country and legal system to remove the uncertainty of justice. As alcohol consumption is the most significant risk factor of domestic violence in Nepal, there should be awareness generation activities to reduce alcohol dependency among its population. All these are pointing towards the link of violence with personal and economic well-being. As suggested by Benson et al. (2004), violence often happen by the influence of neighborhood in which one lives. The economic and social difficulties often act as pathways for violence. Overall findings of this study include: 1) violence against women occur more often and more severe in economically disadvantage neighborhoods; 2) for individuals involved, both objective and subjective forms of economic distress increased the risk of intimate violence against women 3) women who lived in economically disadvantaged communities suffered the greatest risk. Thus, the study suggests to policymakers that violence against women does not occur solely because of an offender's psychological makeup but it has a much broader dimension.

\section{References}

Ali, T. S., Asad, N., Mogren, I., \& Krantz, G. (2011). Intimate Partner Violence in Urban Pakistan: Prevalence, Frequency, and Risk Factors. International Journal of Women's Health, 3, 105-115.

Axinn, W. G., Ghimire, D. J., Williams, N. E., \& Scott, K. M. (2013). Gender, Traumatic Events, and Mental Health Disorders in a Rural Asian Setting. Journal of Health and Social Behavior, 54, 444-461. http://dx.doi.org/10.1177/0022146513501518

Benson, M., \& Fox, G. L. (2004). When Violence Hits Home: How Economics and Neighborhood Play a Role. U.S. Department of Justice, National Institute of Justice, Research in Brief. National Criminal Justice, 205004.

Bott, S., Morrison, A., \& Ellsberg, M. (2005). Preventing and Responding to Gender Based Violence in Middle and Low Income Countries: A Global Review and Analysis (Working Paper No. 3618).

https://openknowledge.worldbank.org/handle/10986/8210

Council of Europe (2006). The Council of Europe Campaign to Combat Violence against Women, Including Domestic Violence. http://www.coe.int/t/dg2/equality/domesticviolencecampaign/fact_sheet_en.asp

Fischbach, R. L., \& Herbert, B. (1997). Domestic Violence and Mental Health: Correlates and Conundrums within and across Cultures. Social Science and Medicine, 45, 1161-1176. http://dx.doi.org/10.1016/S0277-9536(97)00022-1

Hindin, M. J., Kishor, S., \& Ansara, D. L. (2008). Intimate Partner Violence among Couples in 10 DHS Countries: Predictors and Health Outcomes. Calverton, MD: Macro International Incorporated.

International Institute for Population Sciences (IIPS) and Macro International (2007). National Family Health Survey (NFHS-3) (Volume II). Mumbai: IIPS.

Jejeebhoy, S. J. (1998). Association between Wife-Beating and Fetal and Infant Death: Impressions from a Survey in Rural India. Studies in Family Planning, 29, 300-308. http://dx.doi.org/10.2307/172276

Joshi, S. K., \& Kharel, J. (2008). Violence against Women in Nepal-An Overview. The Free Library. 
Karlekar, M. (1998). Domestic Violence. Economic and Political Weekly, 33, 1741-1751.

Lamichhane, P., Puri, M., Tamang, J., \& Dulal, B. (2011). Women’s Status and Violence against Young Married Women in Rural Nepal. BMC Women's Health, 11, 19.

Mahajan, A. (1990). Instigators of Wife Battering. In S. Sood (Ed.), Violence against Women (pp. 1-10). Jaipur: Arihant Publishers.

Moreno, C., Jansen, H.A.F.M., Ellsberg, M., Heise, L., \& Watts C.H. (2005). WHO Multicounty Study on Women's Health and Domestic Violence against Women: Initial Results on Prevalence, Health Outcomes and Women's Responses. Geneva: World Health Organization.

Morrison, A., \& Ellsberg, M. (2005). Preventing and Responding to Gender-Based Violence in Middle and Low-Income Countries: A Global Review and Analysis.

Puri, M., Frost, M., Tamang, J., Lamichhane, P., \& Shah, I. (2012). The Prevalence and Determinants of Sexual Violence against Young Married Women by Husbands in Rural Nepal. BMC Research Notes, 5, 291. http://dx.doi.org/10.1186/1756-0500-5-291

Sharma, S. (2007). Domestic Violence in Nepali Society: Root Cause and Consequences. A Research Report Submitted to SIRF/SNV Nepal, Kathmandu: SIRF/SNV Nepal.

Tjaden, P., \& Thoennes, N. (2000). Full Report of the Prevalence, Incidence and Consequences of Violence against Women: Findings from the National Violence against Women Survey. Washington DC: US Department of Justice and Centre for Disease Control. http://dx.doi.org/10.1037/e514172006-001

UNICEF (2000). Domestic Violence against Women and Girls. No. 6, Innocenti Digest.

United Nations (1993). Declaration on the Elimination of Violence against Women. Proceedings of the 85th Plenary Meeting, United Nations General Assembly, Geneva, 20 December 1993.

http://www.unhchr.ch/huridocda/huridoca.nsf/(Symbol)/A.RES.48.104.En?Opendocument

Visaria, L. (2000). Violence against Women: A Field Study. Economic and Political Weekly, 35, 1742-1751.

World Health Organisation (2002). World Report on Violence and Health. E. G. Krug, L. L. Dahlberg, J. A. Mercy, A. B. Zwi, \& R. Lozano (Eds.). Geneva: World Health Organization. 